
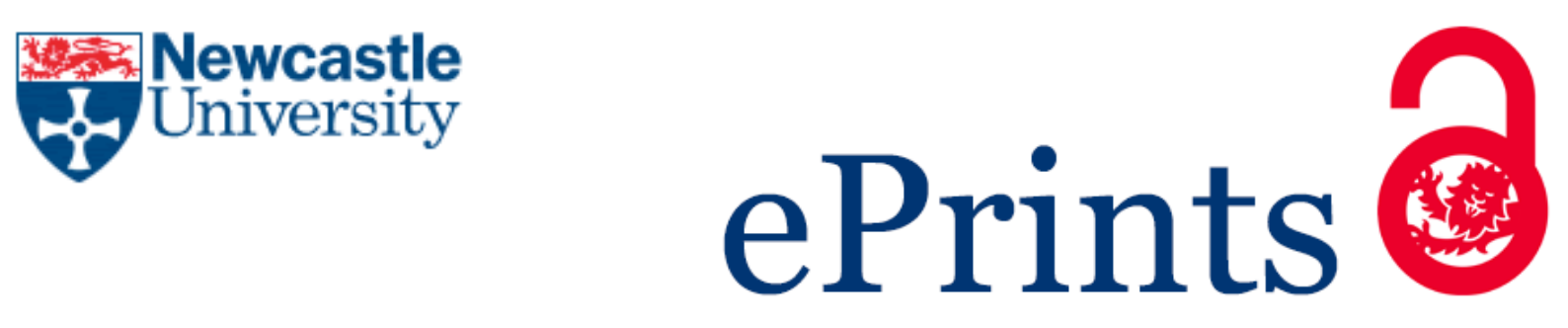

Wang Y, Byrd TA.

Business Analytics-Enabled Decision Making Effectiveness through

Knowledge Absorptive Capacity in Health Care.

Journal of Knowledge Management 2017, 21(3), 517-539.

\title{
Copyright:
}

This is the authors' accepted manuscript of an article that was published in its final definitive form by Emerald, 2017

DOI link to article:

https://doi.org/10.1108/JKM-08-2015-0301

Date deposited:

$04 / 12 / 2016$

Embargo release date:

10 April 2019 


\section{Business Analytics-Enabled Decision Making Effectiveness through Knowledge Absorptive Capacity in Health Care}

\section{Yichuan Wang}

Newcastle University Business School, Newcastle University, UK

\section{Terry Anthony Byrd}

Department of Aviation and Supply Chain Management, Auburn University, Auburn, Alabama, USA

\section{Purpose:}

Drawing on the resource-based theory and dynamic capability view, this study examines the mechanisms by which business analytics capabilities (i.e. the effective use of data aggregation, analytics and data interpretation tools) in healthcare units, indirectly influence decision making effectiveness through the mediating role of knowledge absorptive capacity.

\section{Design/Methodology/Approach:}

Using a survey method, this study collected data from hospitals in Taiwan. Of the 155 responses received, three were incomplete, giving a 35.84\% response rate, with 152 valid data points. Structural equation modelling (SEM) was used to test the hypotheses.

\section{Findings:}

This study conceptualizes, operationalizes and measures the business analytics (BA) capability as a multi-dimensional construct which is formed by capturing the functionalities of BA systems in health care, leading to the conclusion that healthcare units are likely to obtain valuable knowledge through utilizing the data interpretation tools effectively. The effective use of data analysis and interpretation tools in healthcare units indirectly influences decision making effectiveness: an impact that is mediated by absorptive capacity.

\section{Originality/Value:}

This study adds value to the literature by conceptualizing BA capabilities in healthcare and demonstrating how knowledge absorption matters when implementing BA in the decision making process. The mediating role of absorptive capacity not only provides a mechanism by which BA can contribute to decision making practices, but also offers a new solution to the puzzle of the IT productivity paradox in healthcare settings.

Keywords: Business analytics (BA), decision making effectiveness, absorptive capacity, dynamic capability view, resource-based theory, health care

\section{Article Classification: Research paper}

\section{Introduction}

A large amount of clinical data being produced by various healthcare systems galvanizes healthcare organizations into making considerable investments in business analytics (BA) to strengthen their data governance and analysis capabilities (Ghosh and Scott, 2011; Ferranti et al., 2010; Raghupathi and Raghupathi, 2014). BA is defined as a combination of skills, technologies, applications and processes that enables healthcare organizations to analyze an immense volume, variety and velocity of data across a wide range of healthcare networks to support evidence-based decision making and action taking (Wang et al., 2016). BA consists of a number of different analytics techniques such as descriptive, predictive and prescriptive 
analytics (Delen, 2014) and also visualization techniques which are used to expose meaningful information to decision makers. An increasing number of studies have demonstrated the potential of BA for providing tailored, context-sensitive information to guide clinical practice (e.g. Bardhan et al., 2015; Halamka, 2014; Spruit et al., 2014) and explored the impact of BA in terms of its potential for harvesting data-driven insights, supporting evidence-based medicine and improving the quality of care at a lower cost (e.g. Bates et al., 2014; Foshay and Kuziemsky, 2014; Srinivasan and Arunasalam, 2013).

However, despite leveraging BA to derive clinical performance, this is emerging as a top priority for healthcare organizations yet only few healthcare organizations have substantial experience using BA across a broad range of functions (Cortada et al., 2012). Many healthcare organizations are suffering from a lack of understanding about how to transform clinical data into insights, knowledge and informed decisions (Raghupathi and Raghupathi, 2014; Ward et al., 2014). In addition, from a review of prior research on big data, we found that it is unclear what essential technical capabilities can be created from the BA applications that healthcare organizations should acquire to succeed in driving sound decisions and what organizational capabilities enable healthcare organizations to effectively deliver knowledge, triggered by the use of BA systems, to decision makers and other stakeholders. Without an understanding of how BA can be used for decision making, it is harder to convince healthcare practitioners to adopt BA-related technologies for healthcare transformation. This may prevent them from fully embracing BA.

The goal of the research is to identify technical and organisational capabilities influencing BA decision making effectiveness in healthcare. Drawing on the resource-based theory (RBT) and dynamic capabilities view, we first conceptualize BA capabilities in healthcare and then consider the role of knowledge absorptive capacity in the relationship between BA capabilities and decision making effectiveness so that it plays an intermediary role in transforming knowledge obtained from the BA applications into a useful, decision making resource.

The next section of this paper reviews the current research, specifically focusing on exploring the business value of BA. We then move on to examine the theoretical background for BA capability, absorptive capacity and decision making effectiveness to create a basis for developing a research model with a series of hypotheses about the relationships between these proposed constructs. After describing our research methodology and presenting the results, we conclude by discussing our findings and their implications.

\section{Literature Review on Business Analytics Value Creation}

To unveil the role of BA in creating business value, lately, there have been a number of studies focused on developing BA enabled business value models that are generally grounded on an information processing view (IPV) and a resource-based theory (RBT).

From an information processing view (IPV), several studies argue that BA can help organizations process huge amounts of data to acquire meaningful insights so that they can then transform this into organizational knowledge and actionable decisions (Cao et al., 2015; Kowalczyk and Buxmann, 2014; Trkman et al., 2010). To facilitate decision making quality, organizations should design their organizational structure, mechanism and business processes in conjunction with data analysis processes which may reduce the environmental uncertainty and ambiguity of the problem context (Kowalczyk and Buxmann, 2014; Sharma et al., 2014). As regards supply chains, for example, Trkman et al. (2010) report that firms which have the ability to analyze and utilize their information within the different stages of the supply chain (i.e., plan, source, make and deliver) enjoy a superior supply chain performance as a result. In the same vein, Cao and colleagues (2015) have found that utilizing BA, influences information processing capability through the mediation of a data-driven environment, which in turn, has a positive effect on decision making effectiveness. These studies focus on exploiting the use of 
information to improve decision making processes and outcomes. This allows us to understand how business decisions are made through the joint effects of business analytics and information processing mechanisms.

Grounded in the theoretical lens of the RBT and IT capability literature, few studies explain how a firm's unique business analytics capability can be constructed by the configurations of available business analytics technological and organizational resources (e.g. Iş1k et al., 2013; LaValle et al., 2011; Popovič et al., 2012; Wang and Hajli, 2017; Wixom et al., 2013). For example, Wixom et al. (2013) identify two key business analytics capabilities speed to insight and pervasive use - and their underlying dimension from BA resources as playing a role in maximizing business value in the fashion retail industry. Popovič et al. (2012) argue that mature business intelligence (BI) systems, with strong analytical capabilities and data integration, along with knowledge workers who are capable of making full use of complex business intelligence systems, can provide sufficient information to markedly improve decision making processes. Işık et al. (2013) further demonstrate that technological capabilities, such as data quality, user access and the ability to integrate BI with other systems, and BI flexibility, are necessary for creating business value.

In the context of healthcare, Ghosh and Scott (2011) describe how analytical capabilities facilitate data-driven decision making. Their case study shows that Veterans Health Administration's (VHA) BA systems support the physicians' day-to-day clinical practices, such as assessing the risk of a certain surgical procedure by providing the outputs displayed in the dashboards and metrics. BA systems also allow for aggregating patient data to establish measurable improvements that help healthcare managers allocate resources (e.g. determine the resource utilization for the facility and geographic distribution of patients' support service needed) and choose future treatments and policies (e.g. assess the outcomes of policy initiatives and develop medical protocols).

\section{Research model and hypotheses development}

Drawing on the RBT (Barney, 1991; 2001) and IT capability literature (Bharadwaj, 2000), we first conceptualize BA capability by arguing that BA resources - that is, its BA architectural components (i.e., data aggregation, data analysis, and data interpretation) can create BAspecific IT capabilities. The logic behind this argument is that IT capability literature generally adopts a RBT (Barney, 1991; 2001) to argue that a firm's unique IT capability can be constructed by the configurations of its available tangible and intangible IT resources or the synergetic combination of its non-valuable, rare, imperfectly imitable and non-substitutable (VRIN) resources (Santhanam and Hartono, 2003). For example, Pavlou and El Sawy (2006) propose three key dimensions of IT capability that can be identified from new product development (NPD) systems: effective use of project and resource management systems, effective use of knowledge management systems, and effective use of cooperative work systems. With this logic, BA capability could be viewed as a specific type of IT capability.

While we are mindful of developing BA capabilities, we are also concerned for the role of dynamic capability in driving business value from BA. Dynamic capability is a firm's organizational ability to sense and shape opportunities and threats, to seize market opportunities and to maintain competitiveness (Barreto, 2010; Teece, 2007). Dynamic capability view explains how organizations integrate, reconfigure, gain and renew IT resources to match rapidly-changing market environments (Eisenhardt and Martin, 2000; Helfat and Peteraf, 2003; Pavlou and El Sawy, 2006; Teece et al., 1997). We follow this view and the arguments from prior BA literature (Cao et al., 2015; Popovič et al., 2012; Trkman et al., 2010) to consider a mediating role of dynamic capability between BA related constructs and organizational performance since IT alone do not unequivocally facilitate organizational performance (El Sawy et al., 2010). 
Organizational scholars have viewed absorptive capacity as a specific type of dynamic capability (Liu et al., 2013). From an organizational learning perspective, Lichtenthaler (2009) defines it as the ability to assimilate and transform valuable IS knowledge, or to combine new knowledge with existing knowledge by communicating with other organizational members. Fink et al. (2016) and Sharma et al. (2014) argue that this capability plays an important role in transforming the insights triggered by BA into business value. As noted by Ross et al. (2013), BA per se may not magically create benefits until an organization learns how to turn insights or knowledge discovered from data analytics into competitive advantage. Cultivating the ability to identify, extract, transform, and utilize knowledge is essential for healthcare since healthcare decision making is a complex process and heavily dependent on access to knowledge. Schneeweiss (2014) has agreed on this view, suggesting that healthcare organizations must develop the ability to absorb medical knowledge discovered by BA systems and obtain new insights, and apply them to clinical practices in order to create a high quality evidence-based medicine. We thus focus on examining the role of absorptive capacity in the relationship between BA capabilities and decision making effectiveness.

Overall, this study develops a research model (see Figure 1) to represent the mechanisms by which BA capabilities (i.e., the effective use of data warehouse tools, analytics tools, and data visualization tools) in healthcare units can be shown to indirectly influence decision making effectiveness through a key mediating link: absorptive capacity. The following sections will discuss the constructs being used in our research model and associated hypotheses guiding this research.

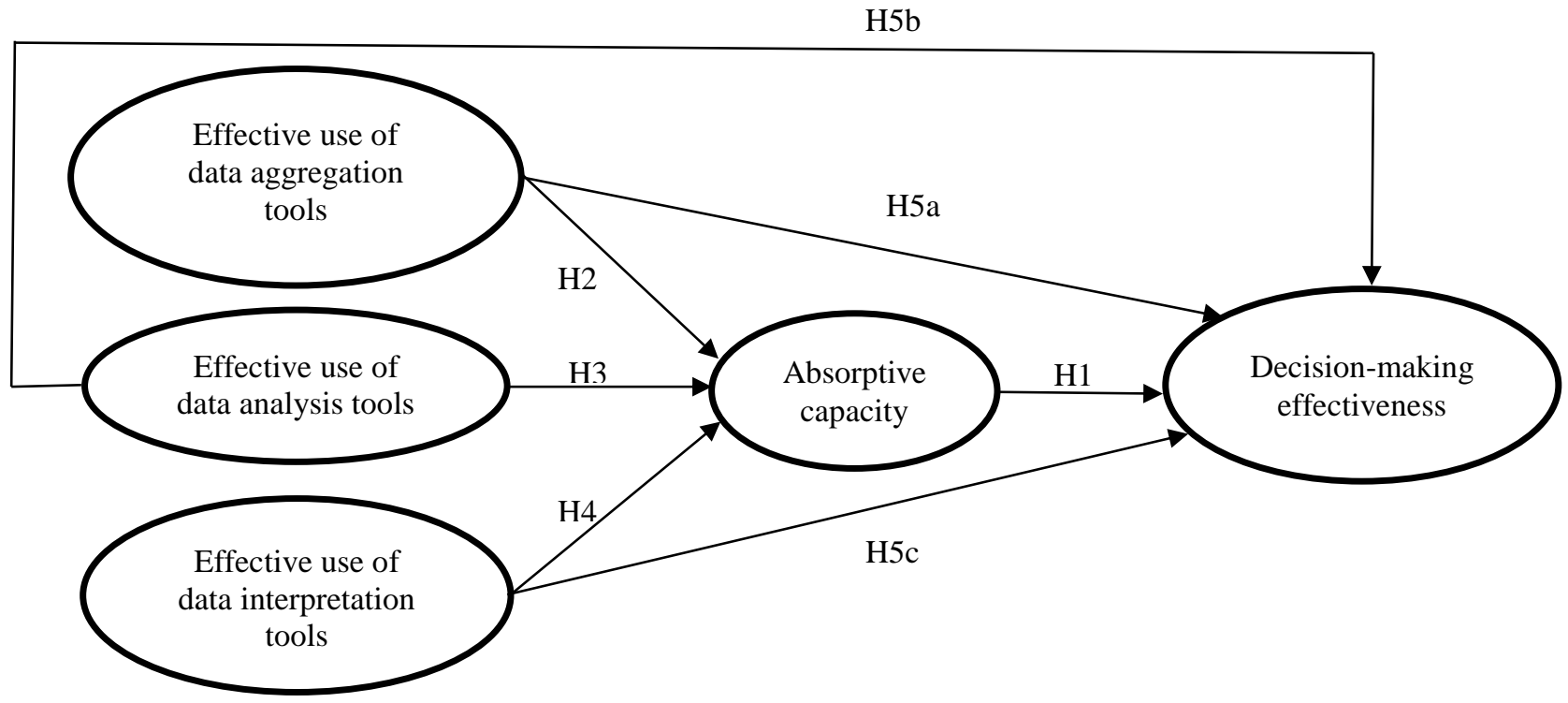

Figure 1. The proposed research model

\subsection{Decision making effectiveness}

Strategic management scholars define decision making effectiveness as the extent to which a decision achieves the objectives established by management at the time it is made (Dean and Sharfman, 1996, p. 372). In the IS literature, decision making effectiveness is an important indicator of IS success and is generally viewed as the dependent variable in IS adoption model (DeLone and McLean, 1992). IS scholars (e.g., Meador et al., 1984; Sanders and Courtney, 1985) have used decision making effectiveness to measure the performance of an information systems.

In the BA literature, decision making effectiveness can be achieved by boosting the speed of a decision (Wixom et al., 2013) and the extent to which organizations understand their customers (Cao et al., 2015; LaValle et al., 2011). These two outcomes have been emphasized 
in the context of analytics-based healthcare systems and individually linked to improved quality of patient care (Barjis et al., 2013; Foshay and Kuziemsky, 2014). Therefore, this study chose enhanced decision making effectiveness as signifying BA success in the healthcare context. The following sections describe the roles of BA capabilities and absorptive capacity, which are proposed to influence decision making effectiveness.

\subsection{Business Analytics Capabilities}

Following Pavlou and El Sawy's (2006) reasoning, we identify the key dimensions of BA capability from the tools and functionalities of BA systems. To this end, we reviewed the relevant academic literature (e.g., Raghupathi and Raghupathi, 2014; Ward et al., 2014), technology tutorials (Hu et al., 2014; Watson, 2014), and case descriptions regarding applying BA systems in healthcare settings. Our starting point was Ward et al.'s (2014) proposed BA architectural framework for health care that elucidates how decisions are made in terms of four architectural layers that begin with data generation and continue through data extraction and data analysis to visualization and reporting, listing the tools and functionalities that are used in each architectural layer. With these dimensions in mind, over 60 big data implementation cases from diverse resources such as major IT vendors, academic journal databases, and healthcare institute reports were reviewed to include, integrate, or drop the items. This review generally affirmed Ward et al.'s framework, apart from the need to integrate data generation and data extraction under a single dimension - data aggregation - because BA systems typically use data warehousing tools to capture, aggregate and ready data from various sources for processing (Raghupathi and Raghupathi, 2014). Based on the results of this review, we propose three key dimensions of BA capability in healthcare: (1) the effective use of data aggregation tools, (2) the effective use of data analysis tools, and (3) the effective use of data interpretation tools, as described below in more detail and summarized in Table 1.

\section{Table 1. Key constructs of BA capability}

\begin{tabular}{|c|c|c|c|}
\hline BA systems & Tools & Key functionalities & Effective use of BA systems \\
\hline $\begin{array}{l}\text { Data } \\
\text { aggregation } \\
\text { tools }\end{array}$ & $\begin{array}{l}\text { - Middleware } \\
\text { - Data warehouse } \\
\text { - Extract-transform- } \\
\text { load (ELT) tools } \\
\text { - Hadoop distributed } \\
\text { file system (HDFS) } \\
\text { - NoSQL database }\end{array}$ & $\begin{array}{l}\text { - Extracting data from } \\
\text { large amounts of data } \\
\text { - Transforming data } \\
\text { into standard formats } \\
\text { - Data storage }\end{array}$ & $\begin{array}{l}\text { - Collect data from external } \\
\text { sources and from various } \\
\text { systems throughout the } \\
\text { healthcare units } \\
\text { - Make data consistent, visible } \\
\text { and easily accessible for } \\
\text { analysis } \\
\text { - Store data into appropriate } \\
\text { databases }\end{array}$ \\
\hline $\begin{array}{l}\text { Data analysis } \\
\text { tools }\end{array}$ & $\begin{array}{l}\text { - Apache Hadoop/Map } \\
\text { Reduce } \\
\text { - Statistical analysis } \\
\text { - OLAP } \\
\text { - Predictive modeling } \\
\text { - Social media } \\
\text { analytics } \\
\text { - Machine learning } \\
\text { - Text mining/NLP }\end{array}$ & $\begin{array}{l}\text { - Processing large } \\
\text { amounts of } \\
\text { unstructured and } \\
\text { semi-structured data } \\
\text { across a massively } \\
\text { parallel cluster of } \\
\text { servers using } \\
\text { Hadoop Map/Reduce } \\
\text { - Real-time analysis } \\
\text { by utilizing stream } \\
\text { computing } \\
\text { - In-database analytics } \\
\text { for analyzing the }\end{array}$ & $\begin{array}{l}\text { - Identify important business } \\
\text { insights to improve costly } \\
\text { healthcare services such as } \\
\text { unnecessary diagnostic tests } \\
\text { and treatments } \\
\text { - Predict pattern of care to } \\
\text { quickly response patient } \\
\text { needs } \\
\text { - Analyze data in near-real or } \\
\text { real time that allows to } \\
\text { quickly respond to } \\
\text { unexpected events }\end{array}$ \\
\hline
\end{tabular}




\begin{tabular}{|c|c|c|c|}
\hline & & $\begin{array}{l}\text { structure of } \\
\text { records }\end{array}$ & $\begin{array}{l}\text { - Analyze social media data } \\
\text { such as patient subjective } \\
\text { opinions, medicine } \\
\text { recommendations and } \\
\text { ratings to understand current } \\
\text { trends in a large population }\end{array}$ \\
\hline $\begin{array}{l}\text { Data } \\
\text { interpretation } \\
\text { tools }\end{array}$ & $\begin{array}{l}\text { - Visual } \\
\text { dashboards/systems } \\
\text { - Reporting } \\
\text { systems/interfaces }\end{array}$ & $\begin{array}{l}\text { - General summary of } \\
\text { data } \\
\text { - Visualization } \\
\text { reporting } \\
\text { - Real-time reporting }\end{array}$ & 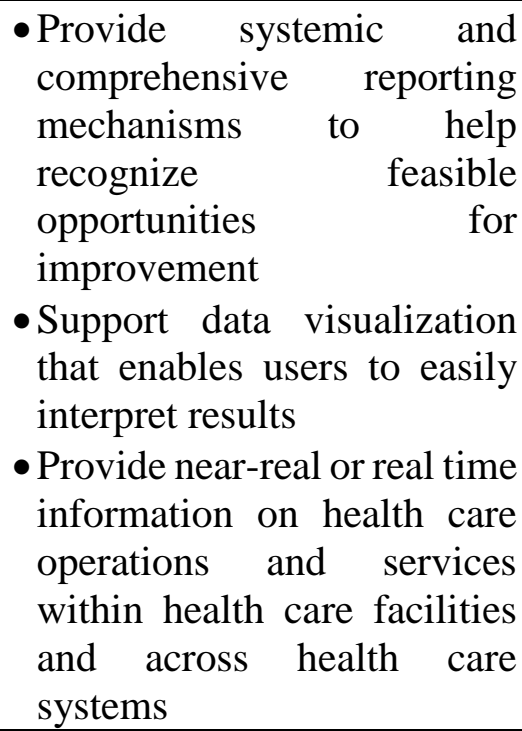 \\
\hline
\end{tabular}

\subsubsection{Effective use of data aggregation tools}

Data aggregation tools are capable of transforming different types of healthcare data (e.g., electronic health records; EHRs, diagnostic or monitoring instrument data, web and social media data, insurance claims/transaction data, pharmacy data, patient-generated data) into a data format that can be read by the data analysis platform. As Raghupathi and Raghupathi (2014) stated, data is intelligently aggregated by three key functionalities in data aggregation tools: acquisition, transformation, and storage.

The primary goal of data acquisition is to collect data from external sources and all the various system components across the healthcare organization. During the data transformation process, transformation engines move, clean, split, translate, merge, sort, and validate the data, as needed. Structured data such as that typically contained in an eclectic medical record is extracted from EHR systems and converted into a specific standard data format, sorted by specified criterion (e.g., patient name, location, or medical history), and then the record validated against data quality rules. Finally, the data are loaded into target databases such as Hadoop distributed file systems (HDFS) or stored in a Hadoop cloud for further processing and analysis. The data storage principles are established based on compliance regulations, data policies and access controls, and data storage methods can be implemented and completed in batch processes or in real time. Since these three functionalities support health care service in value-adding ways, the effective use of data aggregation tools is viewed as a key element of BA capability in health care.

\subsubsection{Effective use of data analysis tools}

Data analysis tools process all kinds of data and perform appropriate analyses to harvest insights (Wald et al., 2014). This is particularly important for transforming patient data into meaningful information that supports evidence-based decision making and useful practices for healthcare organizations. The simple taxonomy of analytics developed by Delen (2014) lists three main kinds of analytics, descriptive, predictive, and prescriptive, each of which is distinguished by the type of data and the purpose of the analysis. 
Descriptive analytics has been widely used in both business intelligence systems and BA systems (Watson, 2014). In hospital settings, descriptive analytics is useful because it allows healthcare practitioners to understand past patient behaviors and how these behaviors might affect outcomes from their EHR database. It also provides high-speed parallel processing, scalability, and optimization features geared toward BA, and offers a private and secure environment for confidential patient records (Wang et al., 2014; 2015).

Predictive analytics allows users to predict or forecast the future for a specific variable based on probability estimation (Phillips-Wren et al., 2015; Watson, 2014). Hadoop/MapReduce, one of the most commonly used predictive analytics-based software products, integrates analytical approaches such as natural language processing (NLP), text mining, and natural networks in a massively parallel processing (MPP) environment. In general, predictive analytics enables users to develop predictive models in a flexible and interactive manner to identity causalities, patterns and hidden relationships between the target variables for future predictions. Applying this to a healthcare context, predictive analytics helps managers disentangle the complex structure of clinical cost, identify best clinical practices, and gain a broader understanding of future healthcare trends based on knowledge of patients' lifestyles, habits, disease management and surveillance (Groves et al., 2013). Predictive analytics also can be used to analyze social media data. Prior research has indicated that this analysis could benefit a healthcare organization in various ways, including helping track and even predict the course of illness through a population, providing non-official channels for disease reporting, and facilitating conversations and interactions with patients (Ward et al., 2014).

Prescriptive analytics is a relatively new kind of analytics that uses a combination of optimization-, simulation-, and heuristics-based predictive modeling techniques such as business rules, algorithms, machine learning and computational modeling procedures (Delen, 2014). Whereas predictive analytics suggests "what will occur in the future" (Watson, 2014, p. 1251), prescriptive analytics offers optimal solutions or possible courses of action to help users decide what to do in the future (Phillips-Wren et al., 2015; Watson, 2014). Prescriptive analytics continually re-predicts and automatically improves prediction accuracy by importing and incorporating new datasets (a combination of structured and unstructured data and business rules) to aid decision makers in solving problems (Riabacke et al., 2012).

Combining these functionalities of data analysis can help increase the efficiency of health care delivery, and we thus proposed the effective use of data analysis tools as a key dimension of BA capability.

\subsubsection{Effective use of data interpretation tools}

Data interpretation tools can be used to produce reports about daily healthcare services to aid managers' decisions and actions. Three key functionalities are involved. The first functionality yields general clinical summaries such as historical reporting, statistical analyses, and time series comparisons and can be utilized to provide a comprehensive view that supports the implementation of evidence-based medicine (Ghosh and Scott, 2011), provides advanced warnings for disease surveillance (Jardine et al., 2014), and guides diagnostic and treatment decisions (Fihn et al., 2014).

Second, data visualization, which is a critical BA feature, facilitates the extraction of meaning from external data by creating helpful visualizations of the information, generally in the form of interactive dashboards and charts. In healthcare, these visualization reports support physicians and nurses' daily operations and help them to make faster and more rational evidence-based decisions (Roski et al., 2014). For example, a Dutch long-term care institution has visualized the number of incidents, the locations where the incidents occurred, and the type of physical damage that resulted by mining a collection of 5,692 incidents over a certain time 
period (Spruit et al., 2014). Displaying frequency tables in the form of visual dashboards has enabled this Dutch long-term care institution to improve patient safety throughout the hospital. Third, real-time reporting, such as alerts and proactive notifications, real time data navigation, and operational key performance indicators (KPIs) can be sent to interested users or made available in the form of dashboards in real time. Since these three functionalities support clinical decision making, the effective use of data interpretation tools is viewed as a key element of BA capability.

\subsection{Absorptive capacity}

Absorptive capacity was conceptualized by Cohen and Levinthal (1990) to describe how a firm absorbs relevant knowledge. Absorptive capacity is believed to be beneficial for firms since it allows them to identify the value of new information gathered from internal and external source, absorb it, and apply it to support their business decisions (Cohen and Levinthal, 1990; Saraf et al., 2013). In IT business value literature, researchers suggest that absorptive capacity acts as a key driver of transforming IT into business value because organizations have to make a considerable effort to acquire and internalize new knowledge from IT (Joshi et al., 2010; Malhotra et al., 2005). With absorptive capacities, a firm can proactively make proper and fast decisions on business strategies than their competitors (Elbashir et al., 2011; Francalanci and Morabito, 2008). In the context of new product development, for example, firms can make timely decisions related to product development and more effectively commercialize innovative ideas into new products if they can create new knowledge more efficiently than other competitors (Lin et al., 2015).

Although the dimensions of absorptive capacity are well-defined, and the importance of absorptive capacity is established in various contexts, it has not been significantly applied to healthcare sectors (Kash et al., 2013). Cohen and Levinthal (1990) originally identify three dimensions of absorptive capacity: identification, assimilation and exploitation. This was later expended to four dimensions: acquisition, assimilation, transformation, and exploitation of knowledge (Flatten et al., 2011; Zahra and George, 2002). We follow this extended conceptualization provided by Flatten et al. (2011) and consider these four capacities together to represent the absorptive capacity of the healthcare organization. Acquisition reflects the process of identifying valuable clinical knowledge from internal resources, such as diagnostic or monitoring instrument data and patient behavioral data and external resources, such as insurance claims/transaction data, pharmacy and lab data. Assimilation means the process of understanding or interpreting the meaning of the clinical knowledge, while transformation refers to the integration of new knowledge with current knowledge, thus preparing the knowledge for application (Zahra and George, 2002). Finally, exploitation illustrates the process of using the integrated knowledge to improve the healthcare organization's existing performance and generate new value ( $\mathrm{Wu}$ and $\mathrm{Hu}, 2012)$. Together, these four capacities reflect healthcare organizations ability to highlight and apply new clinical knowledge, which is critical to clinical performance.

As importance of knowledge management and organizational learning has been acknowledged, prior research indicates that higher absorptive capacity can lead to better healthcare quality improvement (Kash et al., 2013; Lev et al., 2009; Wu and Hu, 2012). Evidence from 12 Israli hospitals, Lev et al. (2009) argue that absorptive capacity is the key to integrate with existing knowledge and improve knowledge flow for its further sharing in order to achieve better performance in a turbulent environment. Taking electronic medical record (EMR) adoption as an example, with absorptive capacities, the members within a healthcare organization can extend their ability from using EMR information properly to identifying how to more fully use the EMR to attain additional financial, quality, or other strategic goals (Kash et al., 2013). Wu and $\mathrm{Hu}$ (2012) have found the impact of absorptive capacity with four 
underlying dimensions (i.e., knowledge acquisition, transfer, integration, and application) on hospital process capabilities and financial and patient performance. Based on these arguments, we believe that a high level of absorptive capacity enables healthcare organizations to transform clinical data into insights that speed up the decision making process and enable medical staffs to respond quickly to customer needs. Hence, the following hypothesis was developed:

\section{Hypothesis 1 (H1): Absorptive capacity will have a positive impact on decision making effectiveness in health care.}

\subsection{The effect of BA capabilities on absorptive capacity}

In health care, several studies have reported that BA capability offers several benefits, including the ability to gather data from current patients to gain useful knowledge for decision making (Ghosh and Scott, 2011), the ability to predict patient behavior via predictive analytics, and the option to retain valuable customers by providing real-time offers (Bardhan et al., 2015; Srinivasan and Arunasalam, 2013). Although acquiring and extracting knowledge from patient data appears to be a challenge due to the need to preserve privacy and maintain trust in the health infrastructure (Chen et al., 2012), several studies have explored ways through which BA capabilities can help healthcare organizations improve their absorptive capacity (e.g., Bates et al., 2014; Groves et al., 2013; Lin et al., 2011). First, the effective use of data aggregation tools can track healthcare data from external sources and the system's IT components throughout the organization's units. Healthcare-related data such as activity and cost data, clinical data, pharmaceutical R\&D data, patient behavior and sentiment data are commonly collected in real time or near real time from payers, healthcare services, pharmaceutical companies, consumers and stakeholders outside healthcare (Groves et al., 2013). Thus, knowledge related to patient' needs is likely to be acquired when the ability to collect, store, and disseminate the data are sufficient.

Second, since significant clinical knowledge and a deeper understanding of patient disease patterns can be gathered from the analysis of EHRs (Lin et al., 2011), data analysis has become an important tool to identify patterns of care and discover associations from massive healthcare records, thus providing a broad overview for evidence-based clinical practice. In hospital settings, the clinical analysis tools in large longitudinal healthcare databases can be used to identify knowledge about drug risk, for example. By integrating BA algorithms into their legacy IT systems, medical staffs can automatically acquire information relating to drug safety decompensation, and treatment optimization by analyzing warning signals triggered by alarm systems (Bates et al., 2014). In addition to clinical analyses, social media analytics allow healthcare organizations to discover knowledge from online healthcare communities (Fan and Gordon, 2014). Social media and its content generated by social interactions and communications among patients not only makes it possible to explore incredible business values, but can also serve as a vital knowledge base for improving healthcare quality and patient satisfaction.

Third, the effective use of data interpretation tools can yield sharable information and knowledge in the form of historical reports, executive summaries, and drill-down queries in an interoperable BA platform. BA has the potential to equip organizations with the reporting systems they need to harness the mountains of heterogeneous data, information, and knowledge that they routinely gather, disentangle intricate customer networks and develop a new portfolio of business strategies for products and services. For example Premier, a healthcare alliance of approximately 3,000 U.S. hospitals, collects data from different departmental systems and sends it to a central data warehouse. After near-real-time data processing, comprehensive and comparable clinical reports of resource utilization and transaction level cost are generated and 
used to help hospital managers to recognize emerging healthcare issues such as patient safety and inappropriate medication use.

Given the increasing embeddedness of BA tools in healthcare operational process, the extent to which a healthcare organization can rapidly acquire, assimilate, and exploit knowledge across its boundaries appears to be primarily dependent upon its ability to leverage and implement BA tools, which is reflected in its BA capabilities. Hence, we developed the following set of hypotheses:

Hypothesis 2 (H2): The effective use of data aggregation tools has a positive impact on absorptive capacity in health care.

Hypothesis 3 (H3): The effective use of data analysis tools has a positive impact on absorptive capacity in health care.

Hypothesis 4 (H4): The effective use of data interpretation tools has a positive impact on absorptive capacity in health care.

\subsection{The mediating role of absorptive capability}

Absorptive capacity can be conceptualized as a higher-order organizational capability (Liu et al., 2013; Roberts et al., 2012) that enable firms to identify, assimilate, and exploit lower-order capabilities (e.g., IT capability and operational capability) to help organizations acquire and sustain a competitive advantage (Cohen and Levinthal, 1990; Grewal and Slotegraaf, 2007; Zahra and George, 2002). IT capabilities, on the other hand, can be viewed as lower-order capabilities that triggering by higher-order capabilities (Pavlou and El Sawy, 2006; 2010). Pavlou and El Sawy (2006) and Roberts et al. (2012) agree, arguing that absorptive capacity serves as a complement to IT capability in creating business value and emphasizing that obtaining capabilities from the use of IT to increase organizational performance cannot be guaranteed unless organizations have sufficient capacity to identify, absorb, transform, and exploit the knowledge that is generated from IT. For instance, Pavlou and El Sawy (2006) contend that the pivotal role of absorptive capability, triggered by the effective use of new product development (NPD) systems, has become the source of competitive advantage in the NPD context. Pavlou and El Sawy's study extends RBT by considering the effect of absorptive capability as a mediating factor linking the impact of NPD related systems with competitive advantage.

Following this logic, few studies view BA capabilities as lower-order capabilities that enabling the development of higher-order organizational capabilities, such as BA-enabled organizational capabilities and dynamic capabilities (Knabke and Olbrich, 2015; Shanks and Bekmanedova, 2012) and adaptive capabilities (Erevelles et al., 2016). In their longitudinal case study of a large financial institution, Shanks and Bekmanedova (2012) found evidence to suggest that BA systems creates firm performance by orchestrating BA enabled organizational capabilities and dynamic capabilities over time. Most recently, Erevelles et al. (2016) integrates RBT with dynamic capability to develop a BA enabled competitive advantage model. Their model not only argues that organizational BA resources allow firms to transform marketing data into consumer insights, but also underscores the realization that dynamic and adaptive capabilities will be triggered by these BA resources, thereby creating marketing value.

Thus, conceptual arguments from prior literature suggest that absorptive capacity mediates the relationship between a healthcare organization's BA capability and decision making effectiveness. High levels of BA capability could enable healthcare organizations to support their decision making. Improved absorptive capacity provides an opportunity for them to speed up their decision making processes, enhance the quality of decision making, and 
deepen their understanding of their patients' needs. In contrast, without it they are less likely to achieve superior decision making effectiveness. We therefore propose indirect impacts of BA in healthcare on decision making effectiveness through the mediating role of absorptive capacity, expressed by the following hypotheses:

Hypothesis 5a (H5a): Absorptive capacity mediates the impact of effective use of data aggregation tools on decision making effectiveness in health care.

Hypothesis 5b (H5b): Absorptive capacity mediates the impact of effective use of data analysis tools on decision making effectiveness in health care.

Hypothesis 5c (H5c): Absorptive capacity mediates the impact of effective use of data interpretation tools on decision making effectiveness in health care.

\section{Research Methodology}

\subsection{Sampling frame and data collection}

This study employed a survey method to collect primary data from Taiwan's healthcare industry. The sample population consisted of Taiwan's hospitals from the most recently available list of hospitals published by the Joint Commission of Taiwan (JCT). The qualifying hospitals should have experience of BA investment for the management and development of healthcare services. We posited that larger hospitals would be more likely to perform BA activities, so to be included in our study, a hospital had to be classified as either a medical center, regional hospital or district hospital. Local clinics and psychiatric hospitals were excluded because they are generally too small to invest in BA. In all, 424 hospitals satisfied all the above criteria and were included in the survey.

This study focuses on whether organizations' decision making effectiveness can be influenced by the use of BA systems. Thus, C-suite business executives, IT managers or senior IT staffs who were actively involved in BA activities were the subjects in this survey. As Wu and $\mathrm{Hu}$ (2012) noted, the implementation of knowledge management practice should be supported by the role of IT. Senior IT employees such as IT managers and senior IT staffs in Taiwan's hospitals are often most responsible for knowledge management practice. Thus, they are knowledgeable and should be considered to be important subjects in this survey. We mailed one questionnaire to each hospital's primary contact, with a follow-up reminder two weeks later to non-respondents; in total, 424 questionnaires were sent to potential participants. Of the 155 responses received, three were incomplete, giving a $35.84 \%$ response rate with 152 valid data points. Of these respondents, 26.97\% $(\mathrm{n}=41)$ were from $\mathrm{C}$-suite business executives, including 17 CEOs and 24 CIOs, $47.37 \%(n=72)$ were IT managers and $25.66 \%(n=39)$ were senior IT staffs. With respect to hospital size, $76.32 \%(n=116)$ of the participating hospitals had at least 200 employees. We recognized the difficulty and importance of finding respondents who can provide insights into various factors and so built in a selection filter by asking the participants to self-check against their level of experience regarding BA before taking the survey. The responses revealed that $78.94 \%(n=120)$ of the participants had been working on BA projects for at least five years, $12.50 \%$ of the participants $(n=19)$ had been working on BA projects for at least three years, and $8.56 \%$ of the participants $(n=13)$ had at least one year BA experience. Since the primary focus of the present study is at the organizational level, the respondents' abundant experience in this area should provide some valuable insights.

\subsection{Measurement}


We developed a series of multi-item measures by either adopting scales that had been previously validated from the existing literature and modifying them appropriately to fit our research context or by developing new scales where there was no existing validated scale. Since the target healthcare organizations are located in Taiwan, all the survey questions were translated into Chinese by one of the authors. The translated copies of questionnaires doublechecked by two researchers who are familiar with both languages for more confident. Following the survey translation procedure recommended by Brislin (1990), the final draft translated to English again for comparing with original one. A few changes to the BA capability scale were made in order to be consistent with the terminology. This process of back translation ensures the face validity and accuracy of the items. Appendix 1 lists the measurement items used. Responses to all the multi-item measures were captured using seven-point Likert-type scales.

Decision making effectiveness: The measurement of this construct was based on reports in the relevant literature, suitably adapted to the context of health care (Cao et al., 2015, LaValle et al. 2011; Wixom et al., 2013). The speed with which a decision is reached is a key component of decision making effectiveness expected from BA (Wixom et al., 2013), while understanding customers refers to the extent to which organizations understand their customers (Cao et al., 2015; LaValle et al., 2011). The quality of decision making was included based on Sanders and Courtney's (1985) suggestions. The resulting 3-item scale was used to capture responses by asking about whether the decision making effectiveness can be satisfied with the aid of BA, with responses ranging from $1=$ completely dissatisfied through $7=$ completely satisfied.

Business analytics capabilities: As BA is still in its infancy in the IS field, there are no validated measurement items for BA capability, so to develop and validate an instrument for BA capability, we incorporated scale development procedures and recommendations from Lewis, Templeton and Byrd (2005) and Mackenzie et al. (2011) as our guidelines. First, we selected appropriate constructs and underlying items by reviewing academic research, technical reports, and case studies. From a system functionality perspective, BA capabilities are operationalized into three dimensions: the effective use of data aggregation tools, the effective use of data analysis tools, and the effective use of data interpretation tools. These initial items aim to assess the extent to which each BA tool is used effectively in healthcare services. Next, content validity was verified and achieved through a pre-test. A small panel of three CIOs who work for healthcare organizations, five MIS researchers, and seven doctoral students in the MIS program were recruited as our content evaluation panel to review our instrument in terms of format, content, understandability, terminology, and ease and speed of completion. This panel was asked to act as judges by sorting items into groups and then critiquing the proposed items. We also asked the judges to identify specific items that should be added or deleted from the instrument, and to provide suggestions for improvement generally. Seven items were modified in accordance with their suggestions. A seven-point Likert-type scale was used for all the BA capability dimensions to capture responses by asking "please rate the effectiveness by which your organization uses the following BA tools in healthcare services", ranging from $1=$ poorly developed to $7=$ well developed.

Absorptive capacity: The measurement of this construct was adopted from Pavlou and El Sawy (2010), and modified to fit the context of health care. A 4-item scale was used to rate the effectiveness by which an organization can acquire, assimilate, transform, and exploit knowledge with the aid of BA. A seven-point Likert-type scale was again used to capture the responses, ranging from $1=$ strongly disagree to $7=$ strongly agree.

\subsection{Non-response bias and common method bias}

Non-response bias. This aspect was assessed by comparing the early (those who responded to the first mailing) and late respondents (those who responded after the reminder), 
in terms of the number of employees using t-tests. The results showed no statistically significant difference between these two groups, indicating that non-response bias did not present a problem for this study.

Common method bias. To reduce common method bias, Podsakoff et al. (2003) suggest the use of specific procedures during both the design and data collection processes. Following these guidelines, we protected respondent-researcher anonymity, provided clear directions to the best of our ability, and proximally separated independent and dependent variables (Podsakoff et al., 2003). We then tested for bias statistically. First, Harman's one factor test (Brewer et al., 1970) was used to determine whether common method bias would pose a threat to the validity of this study's results. The results showed that five factors emerged with eigenvalues greater than 1. Of these, the first component accounted for $31.41 \%$ of the total variance and the unrotated factor solution indicated that no factor accounted for $50 \%$ or more of the variance. Second, following a procedure suggested by Pavlou et al. (2007), we compared correlations among the constructs. The results revealed no constructs with correlations over 0.7, whereas evidence of common method bias ought to have shown considerably higher correlations ( $r>90)$. Consequently, these tests suggest that that common method bias is unlikely to pose a significant threat to the validity of this study.

\section{Analysis and results}

Given our research model and objectives, structural equation modeling (SEM) was used to conduct data analysis. Three reasons drove this choice. First, SEM can examine proposed causal paths among constructs (Gefen et al., 2011). Second, the model does not include secondorder formative constructs. Each indicator was modeled in a reflective manner. Third, our mediating variable, absorptive capacity was measured using multiple items which have to model the measurement error. Thus, SEM is more appropriate than PLS. We analyzed the data using IBM Amos 20.

\subsection{Descriptive statistics and reliability and validity of scale}

Table 2 presents the means, standard deviations, Cronbach's alphas, average variance extracted (AVE), Composite reliability, and construct correlations. The Cronbach's alphas (ranging from 0.80 to 0.91 ) indicate a satisfactory degree of internal consistency and reliability for the measures (Bollen and Lennox, 1991), with all values well above .70 (Nunnally and Bernstein, 1994). Construct reliability was assessed based on the composite construct reliabilities (CR) (Hair et al., 2010, p. 687). As shown in Table 3, the CRs ranged from 0.93 and 0.98 , well over the commonly accepted cutoff value of .70 (Hair et al., 2010), thus demonstrating the adequate reliability of the measures.

Table 2. Descriptive Statistics and Correlations

\begin{tabular}{|l|l|l|l|l|l|l|l|l|l|}
\hline Variable & Mean & S.D. & $\alpha$ & CR & 1 & 2 & 3 & 4 & 5 \\
\hline Effective use of data aggregation & 4.40 & 1.42 & 0.91 & 0.92 & 0.78 & & & & \\
\hline Effective use of data analysis & 4.65 & 1.33 & 0.84 & 0.85 & 0.05 & 0.59 & & & \\
\hline Effective use of data interpretation & 3.97 & 1.20 & 0.91 & 0.91 & $0.19^{*}$ & 0.05 & 0.78 & & \\
\hline Absorptive capacity & 3.66 & 1.10 & 0.85 & 0.86 & $0.21^{* *}$ & $0.19^{*}$ & $0.50^{* *}$ & 0.60 & \\
\hline Decision-making effectiveness & 4.32 & 1.14 & 0.80 & 0.80 & 0.11 & $0.17^{*}$ & $0.47^{* *}$ & $0.47 * *$ & 0.57 \\
\hline
\end{tabular}

Note: $\mathrm{N}=152$; AVEs on diagonal

CR: Composite reliability; ${ }^{*} \mathrm{p}<0.05, * * \mathrm{p}<0.01, * * * \mathrm{p}<0.001$

Discriminant validity was first assessed by examining the construct correlations. Although there are no firm rules, inter-construct correlations below $|.7|$ are generally considered to 
provide evidence of measure distinctness, and thus discriminant validity. None of the construct correlations were greater than .7, which demonstrates discriminant validity (see Table 3 ). Another way to examine discriminant validity is to compare the AVE to the squared interconstruct correlation. When the AVE is larger than the corresponding squared inter-construct correlation estimates, this suggests that the indicators have more in common with the construct they are associated with than they do with other constructs, which again provides evidence of discriminant validity. The data shown in Table 3 suggests the adequate divergent validity of the measures.

\subsection{Exploratory factor analysis}

For the measurement property evaluation, exploratory factor analysis (EFA) was conducted to explore the factor structure. Before performing the factor analysis, we verified that the data were appropriate for factor analysis using the Kaiser-Meyer-Olkin (KMO) test and the Bartlett sphericity test. The results of both tests indicated that a factor analysis would be useful given our data $\left(\mathrm{KMO}=0.815 ; \chi^{2}=1502.457 ; d f=136 \mathrm{p}<.000\right)$. The initial factor analysis using principal components analysis extracted five factors that were evident on the scree plot, all with an eigenvalue greater than one. Factor loadings for the effective use of the data aggregation block ranged from 0.894 to 0.928 , the effective use of the data analysis block ranged from 0.675 to 0.865 , the effective use of data interpretation from 0.819 to 0.910 , the absorptive capacity block ranged from 0.686 to 0.850 , and the decision making effectiveness block ranged from 0.673 to 0.857 . Overall, the results for EFA achieved standard factor loadings of 0.5 as the cut-off significance, confirming that individual factors can indeed be identified in a given block of dimensions.

\subsection{Confirmatory factor analyses and measurement model}

A measurement model was then analyzed to assess the measurement quality of the constructs using a confirmatory factor analysis (CFA). The measurement model consisted of five factors. The loading ranges for these five factors were as follow: the effective use of data aggregation, 0.816 to 0.932 ; the effective use of data analysis, .574 to .825 ; the effective use of data interpretation, 0.830 to 0.945 ; absorptive capacity, 0.674 to 0.845 ; and decision making effectiveness, 0.700 to 0.793 . The model chi-square was not statistically significant $\left(\chi^{2}(109)\right.$ $=143.117, \mathrm{p}>.05)$, which indicates that the exact fit hypothesis should be accepted. The comparative fit index (CFI) was 0.976, which exceeds the cutoff value of .80, and the standardized root mean square residual (SRMR) was .0557. The root mean square error of the approximation (RMSEA) was .046, which is less than .08. Thus, we concluded that our data adequately fit the measurement model.

\subsection{Mediating effect testing}

To test the mediating effects of absorptive capacity, we compared five alternative models in terms of their fit statistics and path coefficients. The fit statistics for the models are shown in Table 4. First, the proposed model (Model A) in which the path coefficients among the five latent variables were freely estimated was tested. The absolute value of and CFI was well above .95 and SRMR and RMSEA were both less than .08 for Model A. Then, a series of alternative structural models were tested against each other. After comparing Model B, in which all path coefficients among the five latent variables were constrained to zero, to the direct model (Model C), in which all path coefficients to and from absorptive capacity were constrained to zero, we found that Model $\mathrm{C}$ produced a significantly better fit to the data compared to Model B. In Model C, we examined the impact of BA captivity alone on decision making effectiveness. The results revealed that the path coefficient was significant from the effective use of data interpretation tools to decision making effectiveness, but insignificant from the 
effective use data analysis and aggregation tools to decision making effectiveness. Next, Model $\mathrm{D}$, in which all path coefficients from the three forms of BA capabilities were constrained to zero, was also compared to the baseline model (Model B). Hypothesis 1 was supported because Model D produced a significantly better fit to the data compared to Model B and the path coefficient from absorptive capacity to decision making effectiveness was significant.

The full mediation model (Model E), in which all path coefficients from the three forms of BA capabilities to decision making effectiveness were constrained to zero, was then compared to Model C and Model D. The results showed that Model E produced a significantly better fit to the data compared to either Model C or Model D, indicating that the effective use of data analysis and interpretation tools positively affects absorptive capacity. Thus, Hypothesis 3 and Hypothesis 4 were supported, but Hypothesis 2 was not supported. Finally, the proposed model (Model A) was compared to Model E; the results showed that Model A fit the data slightly better than Model E. We thus concluded that our proposed model (Model A) provided the most parsimonious fit to the data.

The paths and parameter estimates for the proposed model (Model A) are shown in Figure 2 , which indicates that absorptive capacity had the greatest association with decision making effectiveness and the path coefficients from business capabilities to absorptive capacity became insignificant after adding a mediator (in this case, absorptive capacity). While it mediated the relationships between the effective use of data analysis tools and both the effective use of data interpretation tools and the decision making effectiveness, it failed to mediate the relationship between the effective use of data aggregation tools and decision making effectiveness because the path coefficient between effective use of data aggregation tools and absorptive capacity was not significant. As the direct effects of the effective use of data analysis tools on decision making effectiveness was not significant, this indicates that absorptive capacity fully mediated the relationship between them. However, as the direct effects of effective use of data interpretation tools on decision making effectiveness was significant, the absorptive capacity only partially mediated the relationship between them.

To further confirm the mediating role of absorptive capacity, a bootstrapping analysis was used to assess the significance of each indirect effect. As recommended by Cheung and Lau (2008), we set the number of bootstrap samples as 1,000. The results showed that the two-sided bias-corrected bootstrap confidence interval for the indirect effect of data interpretation tools on decision making effectiveness through absorptive capacity was [0.269, 0.511], that for the indirect effect of data aggregation tools on decision making effectiveness was [-0.016, 0.0149] and for the indirect effect of data analysis tools on decision making effectiveness it was [0.018, 0.314]. Thus, the indirect (mediated) effects of data analysis and interpretation tools on decision making effectiveness were both significant, whereas the indirect effect of data aggregation tools on the decision making effectiveness was not significant, consistent with the aforementioned results. Thus, Hypotheses $5 \mathrm{~b}$ and $5 \mathrm{c}$ were supported, but Hypothesis 5a was not supported.

Table 3. Model fit summary and nested model comparisons

\begin{tabular}{|c|c|c|c|c|c|c|c|}
\hline Model & Chi-square & df & p-value & $\Delta \chi 2$ & CFI & SRMR & RMSEA (90C.I.) \\
\hline A & 150.248 & 112 & .009 & - & 0.973 & 0.0785 & $0.048(0.025,0.066)$ \\
\hline B & 245.963 & 119 & .000 & 95.715 & 0.911 & 0.1962 & $0.840(0.069,0.099)$ \\
\hline C & 209.907 & 116 & .000 & 59.659 & 0.935 & 0.1719 & $0.073(0.057,0.089)$ \\
\hline D & 210.907 & 118 & .000 & 60.659 & 0.935 & 0.1730 & $0.072(0.056,0.088)$ \\
\hline E & 162.321 & 115 & .002 & 12.073 & 0.967 & 0.0880 & $0.052(0.032,0.070)$ \\
\hline
\end{tabular}

Notes: SRMR = standard root mean square residual; CFI = comparative fit index; RMSEA = root mean square error of approximation.

The proposed model served as the baseline for chi-square difference testing

Model A: the proposed model, no path coefficients among the five latent variables were constrained to zero.

Model B: all path coefficients among the five latent variables were constrained to zero. 
Model C: all path coefficients to and from absorptive capacity were constrained to zero.

Model D: all path coefficients from BA capabilities were constrained to zero.

Model E: all path coefficients from the BA capabilities to decision-making effectiveness were constrained to zero.

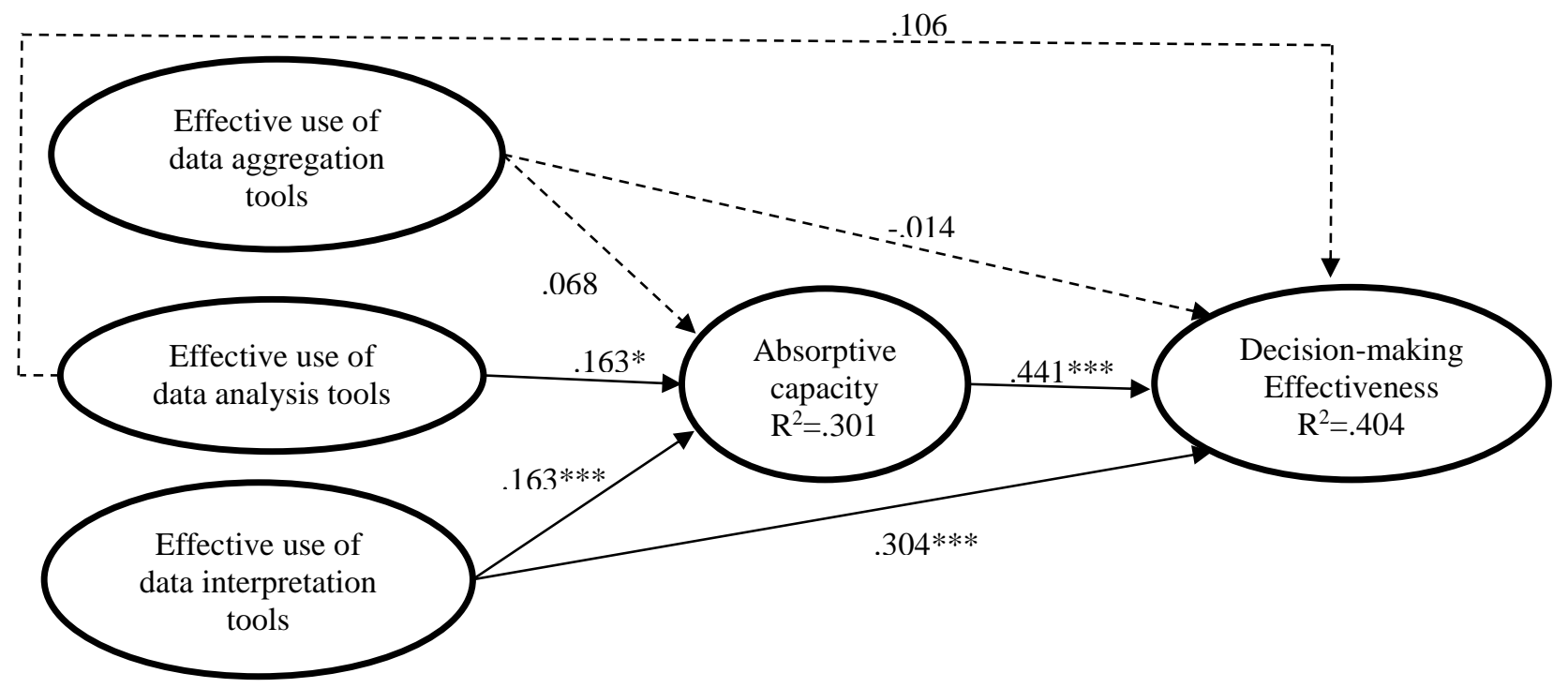

Figure 2. Path diagram and standardized estimates

Note: Summary of standardized path coefficients for the hypothesized model with the full sample $(\mathrm{N}=152)$. Solid lines represent significant coefficients, and dotted lines represent non-significant coefficients, $* \mathrm{p}<.05 ; * * \mathrm{p}<.01 ; * * * \mathrm{p}<.001$.

\section{Discussion}

Big data related technologies have become the most influential IT innovations in the last decade. Medical professionals urge their peer institutions to leverage the new data governance, collection and analysis approaches for gaining a holistic understanding of health from largescale patient data that goes beyond the current state of knowledge about treatments and diseases. The main objective of this research was to advance our understanding of the way BA enables healthcare units to enjoy better decision making through the absorption of the new knowledge provided by the BA systems. By applying the RBT and the dynamic capability view, this study proposes a conceptual model in which BA capabilities, as lower-order IT capabilities, exert influence on decision making effectiveness through a higher-order capability, namely absorptive capacity. The empirical evidence collected for this study supports five key findings.

First, the results strongly support the claim that healthcare organizations' BA capabilities - both the effective use of data analysis and interpretation tools - can help improve its absorptive capacity. This finding is consistent with prior studies that emphasized the notion 
that the amplifying role of lower-order IT or operational capabilities can be developed to improve organizational capabilities (e.g., Liu et al., 2013; Pavlou and El Sawy, 2006; 2010).

Second, with respect to indirect effect, the effective use of interpretation tools in healthcare units indirectly influences decision making effectiveness, an impact that is mediated by absorptive capacity. This means that hospitals are likely to create valuable knowledge to make sound clinical decisions as they utilize visual dashboards and metrics effectively (Jardine et al., 2014; Spruit et al., 2014).

Third, consistent with the dynamic capabilities view which contends the effective of IT capability on competitive advantage are fully mediated by dynamic capability (Pavlou and El Sawy, 2006; 2010), the mediating effect test indicates the full mediation of absorptive capacity on the relationship between the effective use of data analysis tools and decision making effective. Fourth, as we expected, the findings have highlighted the critical role of absorptive capacity in achieving decision making effectiveness in health care.

Finally, the results of this study do not support the hypothesis on the association of the effective use of data aggregation tools and absorptive capacity as well as decision making effectiveness. A possible explanation is that the majority of respondents (74.34\%) were from the top-level management (i.e., CEO, CIO) and middle-level management (i.e., IT managers). They are not responsible for aggregating and dealing with patient data in back-end systems. Although data aggregation is a precursor requirement to data analysis and interpretation and remains important, many care providers are suffering from data aggregation-related issues such as the lack of data standards and data integration, data overload issues, and barriers to the collection of high-quality data (Ashrafi et al., 2014; Ward et al., 2014) Thus, healthcare managers have to be aware of the importance of data aggregation tools as implementing BA systems. Based on these findings, we can offer some useful insights regarding the theoretical and managerial implications of these findings.

\subsection{Theoretical contributions and implications}

One of the most discussed questions in the fields of IS and healthcare informatics is how to use patient data and analysis effectively to support its clinical decisions. This study makes three main contributions towards this question. First, the conceptualization and operationalization of the construct of BA capability has contributed to the development of a deeper understanding of BA. Previous research has sought to measure BA capability by modeling it as a one-dimension construct, instead choosing to focus solely on examinations of the data analysis process (Cao et al., 2015). However, such approaches may unintentionally overlook other important facets of BA capability, such as its ability to visualize data. Thus, the construct of BA capability draws on a broader view of IT functionality that allows us to capture the concept of BA more fully by reviewing its functionalities and how it is actually implemented in real-world healthcare units to conceptualize the BA capability. This conceptualization is the first step towards building a much needed body of knowledge on the business value of BA and provides researchers with a useful lens through which to examine the effectiveness of BA systems in supporting various organizational practices.

Second, in this study, a theoretical basis for the relationship between BA capability and decision making effectiveness was elucidated by adopting a knowledge absorptive capacity perspective that is rooted in RBT and dynamic capability view. Our results demonstrate how knowledge absorption matters when implementing BA to the decision making process by examining its mediation role. Specifically, our finding suggests that the effective use of data analysis and aggregation tools has no business value, thus affirming the commonly held view of the IT productivity paradox in the healthcare context (Jones et al., 2012). However, the mediating role of absorptive capacity not only provides a mechanism by which BA can 
contribute to decision making practices, but also offers a new solution to the puzzle of the IT productivity paradox in healthcare settings.

Finally, previous studies have developed the BA value creation models to demonstrate the managerial, economic, and strategic impacts of BA from the different theoretical perspectives. Yet, these are generic and do not meet the healthcare industry's particular requirements (Foshay and Kuziemsky, 2014). Thus, our proposed model would help healthcare organizations recognize the business value of BA and guide them through the process to effectively utilize BA for decision making in clinical settings.

\subsection{Implications for practice}

For project leaders who are responsible for BA adoption, this study provides a set of interesting insights that may affect the scope of their current BA projects. First, even if IT vendors have enthusiastically advocated the potential benefits of BA when used for various business practices, BA implementation requires organizational changes if it is to be effective. In addition to the technological issues of $\mathrm{BA}$, managers must also turn their attention to integrating knowledge management into BA initiatives, focusing particularly on ways to harness BA-generated knowledge. Healthcare organizations must constantly seek and disseminate new knowledge obtained by analyzing patient data to respond to industry regulations and market needs. Our findings suggest that the ability to obtain and apply knowledge becomes critical for healthcare organizations since patient data per se cannot generate value. Thus, a strong knowledge management protocol could add tremendous value during BA implementation.

Second, our results show that data interpretation is a crucial capability that directly impacts decision making effectiveness. Although BA can create convenient summarized reports or charts, the key to making these reports meaningfully is to equip managers and employees with relevant professional skills. Incorrect interpretation of the reports generated could lead to serious errors of judgment and questionable decisions. Managers should provide suitable analytical training courses for the employees who will play a critical support role in the new information-rich work environment if organizations are to make best use of their new opportunities to transfer data into knowledge.

\section{Conclusion}

Notwithstanding the above-mentioned contributions and implications, our study is inevitably subject to some limitations. First, different industries have different needs, goals and expectations when implementing BA solutions. We targeted healthcare industries for this study, so the generalizability of the results is limited, because data were only collected from a limited sample consisting of large hospitals in Taiwan. Thus, our findings are not applicable to healthcare industries in other countries. Second, the sample size used for validating the BA capability scale was relatively small, although the representativeness of our sample may overcome the sample size issue to some extent. More than $70 \%$ of the participants in this study served as senior IT executives and were thus able to provide strategic overviews of the BA implementation in their healthcare organizations. Meanwhile, by carefully taking various steps for scale development, we tried to minimize the potential bias. Third, in order to make stronger conclusions from research, further empirical research should validate the scales of business analytics capability by utilizing larger samples. Finally, given its exclusive focus on BA capability, our study does not consider other possible factors contributing to BA success.

In response to the limitations of the current study, we offer some suggestions for future research. A more comprehensive study is now needed that examines other factors that may serve as enablers or moderating or mediating roles for this path. As the business value of IT 
research suggests, several human IT resource (e.g., the analytical personnel's skills), other organizational capability factors (e.g., dynamic capability, improvisational capabilities), organizational complementary resources (data government, synergy, and culture), and environmental factors (market and environmental turbulent) could all play a role and should thus be examined. Also, rather than examining the aforementioned factors with singular causation and linear associations, future studies could seek to capture the complex interactions of the interdependencies among BA capabilities and other organizational elements, and examine how different configurations create improved business value.

In conclusion, our primary research objective was to unravel the relationships among BA capability, absorptive capacity and decision making effectiveness. With our focus on the role of absorptive capacity, we found that BA systems may indeed reveal new opportunities for transforming decision making process. Consequently, the findings of this study provide interesting new insights into knowledge management, contributing to the BA literature by proposing a BA-enabled decision making effectiveness model that takes into account the effect of absorptive capacity.

\section{Acknowledgements}

A previous version of the paper was presented at the 2015 Pre-ICIS (International Conference on Information Systems) SIG GlobDev 8th Annual Workshop, Fort Worth, Texas, December 13,2015 . The authors are very thankful to the attendants in this workshop for the valuable feedback received. The authors also would like to acknowledge Ms. Muyin Lo from a southern medical center in Taiwan and Dr. Chiahui Yu from National Chengchi University who assisted in the data collection.

\section{Appendix 1: Measurement Items}

\section{Effective use of data aggregation tools (Newly developed)}

Please rate the effectiveness by which your organization uses the following business analytics tools in the healthcare services.

1. Collect data from external healthcare sources and from various health systems throughout your organization.

2. Make patient records consistent, visible and easily accessible for further analysis.

3. Store patient data into appropriate databases.

Effective use of data analysis tools (Newly developed)

1. Identify important business insights and trends to improve healthcare services.

2. Predict patterns of care in response to patient needs.

3. Analyze data in near-real or real time that allows responses to unexpected clinical events.

4. Analyze social media data to understand current trends from a large population.

Effective use of data interpretation tools (Newly developed)

1. Provide systemic and comprehensive reporting to help recognize feasible opportunities for care improvement.

2. Support data visualization that enables users to easily interpret results.

3. Provide near-real or real time information on health care operations and services within healthcare facilities and across health care systems.

Absorptive capacity (Pavlou and El Sawy, 2010)

Please rate the effectiveness by which your organization can acquire, assimilate, transform, and exploit knowledge with the aid of business analytics.

1. We have effective routines to identify value, and import new information and knowledge.

2. We have adequate routines to assimilate new information and knowledge. 
3. We are effective in transforming existing information into new knowledge.

4. We are effective in utilizing knowledge into new services.

\section{Decision making Effectiveness}

1. As a result of business analytics systems, the quality of decisions has improved (Sanders and Courtney, 1985).

2. As a result of business analytics systems, the speed at which we analyze decisions has increased. (LaValle et al., 2011; Wixom et al., 2013)

3. As a result of business analytics systems, we have an increased understanding of our customers. (Cao et al., 2015) 


\section{References}

Ashrafi, N., Kelleher, L. and Kuilboer, J. P. (2014), "The impact of business intelligence on healthcare delivery in the USA", Interdisciplinary Journal of Information, Knowledge, and Management, Vol. 9, pp. 117-130.

Bardhan, I., Oh, J. H., Zheng, Z. and Kirksey, K. (2014), "Predictive analytics for readmission of patients with congestive heart failure", Information Systems Research, Vol. 26 No. 1, pp. 19-39.

Barjis, J., Kolfschoten, G. and Maritz, J. (2013), “A sustainable and affordable support system for rural healthcare delivery”, Decision Support Systems, 56, 223-233.

Barney, J. (1991), "Firm resources and sustained competitive advantage", Journal of Management, Vol. 17 No. 1, pp. 99-120.

Barney, J.B. (2001), "Resource-based theories of competitive advantage: a ten-year retrospective on the resource-based view", Journal of Management, Vol. 27 No. 6, pp. 643-650.

Bates, D.W., Saria, S., Ohno-Machado, L., Shah, A. and Escobar, G. (2014), "Big data in health care: using analytics to identify and manage high-risk and high-cost patients", Health Affairs, Vol. 33 No. 7, pp. 1123-1131.

Bharadwaj, A. S. (2000), "A resource-based perspective on information technology capability and firm performance: an empirical investigation", MIS Quarterly, Vol. 24 No. 1, pp. 169196.

Bollen, K. and Lennox, R. (1991), "Conventional wisdom on measurement: a structural equation perspective", Psychological Bulletin, Vol. 110 No. 2, pp. 305-314.

Brewer, M.B., Campbell, D.T. and Crano, W.D. (1970), "Testing a single-factor model as an alternative to the misuse of partial correlations in hypothesis-testing research", Sociometry, Vol. 33 No. 1, pp. 1-11.

Brislin, R.W. (1990). "Applied cross-cultural psychology: an introduction”, in Brislin RW (Ed.), Applied Cross-cultural Psychology. Newbury Park, CA: Sage, pp. 9-33.

Cao, G., Duan, Y. and Li, G. (2015), "Linking business analytics to decision making effectiveness: a path model analysis", IEEE Transactions on Engineering Management, Vol. 62 No. 3, pp. 384-395.

Chen, H., Chiang, R.H.L. and Storey, V.C. (2012), "Business intelligence and analytics: from big data to big impact", MIS Quarterly, Vol. 36 No. 4, pp. 1165-1188.

Cheung, G.W. and Lau, R.S. (2008), "Testing mediation and suppression effects of latent variables: bootstrapping with structural equation models", Organizational Research Methods, Vol. 11 No. 2, pp. 296-325.

Cohen, W.M. and Levinthal, D.A. (1990), Absorptive capacity: a new perspective on learning and innovation. Administrative Science Quarterly, 35(1), 128-152.

Cortada, J.W., Gordon, D. and Lenihan, B. (2012), The Value of Analytics in Healthcare: From Insights to Outcomes. Somers, NY: IBM Global Business Services.

Dean, J.W. and Sharfman, M.P. (1996), "Does decision process matter? A study of strategic decision-making effectiveness", Academy of Management Journal, Vol. 39 No. 2, pp. 368-392.

Delen, D. (2014). Real-World Data Mining: Applied Business Analytics and Decision Making. FT Press.

DeLone, W.H. and McLean, E.R. (1992), "Information systems success: the quest for the dependent variable", Information Systems Research, Vol. 3 No. 1, pp. 60-95.

Elbashir, M.Z., Collier, P.A. and Sutton, S.G. (2011), "The role of organizational absorptive capacity in strategic use of business intelligence to support integrated management control systems", The Accounting Review, Vol. 86 No. 1, pp. 155-184. 
Erevelles, S., Fukawa, N. and Swayne, L. (2016), "Big data consumer analytics and the transformation of marketing", Journal of Business Research, Vol. 69 No. 2, pp. 897-904.

Fan, W. and Gordon, M.D. (2014), "The power of social media analytics", Communications of the ACM, Vol. 57 No. 6, pp. 74-81.

Ferranti, J.M., Langman, M.K., Tanaka, D., McCall, J. and Ahmad, A. (2010), "Bridging the gap: leveraging business intelligence tools in support of patient safety and financial effectiveness", Journal of the American Medical Informatics Association, Vol. 17 No. 2, pp. 136-143.

Fihn, S.D., Francis, J., Clancy, C., Nielson, C., Nelson, K., Rumsfeld, J., Cullen, T., Bates, J. and Graham, G. L. (2014), "Insights from advanced analytics at the Veterans Health Administration”, Health Affairs, Vol. 33 No. 7, pp. 1203-1211.

Fink, L., Yogev, N., and Even, A. (2016). "Business intelligence and organizational learning: An empirical investigation of value creation processes", Information \& Management. doi:10.1016/j.im.2016.03.009.

Flatten, T.C., Engelen, A., Zahra, S.A. and Brettel, M. (2011), "A measure of absorptive capacity: scale development and validation", European Management Journal, Vol. 29 No. 2, pp. 98-116.

Foshay, N. and Kuziemsky, C. (2014), "Towards an implementation framework for business intelligence in healthcare", International Journal of Information Management, Vol. 34 No. 1, pp. 20-27.

Francalanci, C. and Morabito, V. (2008), "IS integration and business performance: the mediation effect of organizational absorptive capacity in SMEs", Journal of Information Technology, Vol. 23 No. 4, pp. 297-312.

Gefen, D., Rigdon, E.E. and Straub, D. (2011), “An update and extension to SEM guidelines for administrative and social science research", MIS Quarterly, Vol. 35 No. 2, pp. iii-xiv.

Ghosh, B. and Scott, J.E. (2011), "Antecedents and catalysts for developing a healthcare analytic capability", Communications of the Association for Information Systems, Vol. 29 No. 1, pp. 395-409.

Grewal, R. and Slotegraaf, R. J. (2007), "Embeddedness of organizational capabilities". Decision Sciences, Vol. 38 No. 3, pp. 451-488.

Groves, P., Kayyali, B., Knott, D. and Kuiken, S.V. (2013), The "Big Data” Revolution in Healthcare: Accelerating Value and Innovation. McKinsey \& Company.

Hair Jr.,J.F., Black, W., Babin, B. and Anderson, R. (2010), Multivariate data analysis (7th ed.). Pearson Education Inc.

Halamka, J.D. (2014), "Early experiences with big data at an academic medical center", Health Affairs, Vol. 33 No. 7, pp. 1132-1138.

Hu, H., Wen, Y., Chua, T. S., and Li, X. (2014), "Toward scalable systems for big data analytics: a technology tutorial", Access, IEEE, Vol. 2, pp. 652-687.

Işı1k, Ö., Jones, M. C. and Sidorova, A. (2013), "Business intelligence success: the roles of BI capabilities and decision environments", Information \& Management, Vol. 50 No. 1, pp. 13-23.

Jardine, A., Mullan, N., Gudes, O., Cosford, J., Moncrieff, S., West, G., Xiao, J., Yun, G. and Someford, P. (2014), "Web-based geo-visualisation of spatial information to support evidence-based health policy: A case study of the development process of 'Health Tracks"', Health Information Management Journal, Vol. 43 No. 2, pp. 7-16.

Jones, S.S., Heaton, P.S., Rudin, R.S. and Schneider, E.C. (2012), "Unraveling the IT productivity paradox-lessons for health care", New England Journal of Medicine, Vol. 366 No. 24, pp. 2243-2245. 
Joshi, K. D., Chi, L., Datta, A. and Han, S. (2010), "Changing the competitive landscape: continuous innovation through IT-enabled knowledge capabilities", Information Systems Research, Vol. 21 No. 3, pp. 472-495.

Kash, B.A., Spaulding, A., Gamm, L. and Johnson, C.E. (2013). "Health care administrators' perspectives on the role of absorptive capacity for strategic change initiatives: A qualitative study", Health Care Management Review, Vol. 38 No. 4, pp. 339-348.

Kowalczyk, D.W.I.M. and Buxmann, P. (2014), "Big data and information processing in organizational decision processes", Business \& Information Systems Engineering, Vol. 6 No. 5, pp. 267-278.

LaValle, S., Lesser, E., Shockley, R., Hopkins, M.S. and Kruschwitz, N. (2011), "Big data, analytics and the path from insights to value", MIT Sloan Management Review, Vol. 52 No. 2, pp. 21-31.

Lev, S., Fiegenbaum, A., and Shoham, A. (2009). "Managing absorptive capacity stocks to improve performance: Empirical evidence from the turbulent environment of Israeli hospitals", European Management Journal, Vol. 27 No. 1, pp. 13-25.

Lewis, B.R., Templeton, G.F. and Byrd, T.A. (2005), "A methodology for construct development in MIS research", European Journal of Information Systems, Vo.14, No.4, pp. 388-400.

Lichtenthaler, U. (2009), "Absorptive capacity, environmental turbulence, and the complementarity of organizational learning processes", Academy of Management Journal, Vol. 52 No. 4, pp. 822-846.

Lin, Y., Brown, R. A., Yang, H.J., Li, S., Lu, H. and Chen, H. 2011. "Data mining large-scale electronic health records for clinical support", IEEE Intelligent Systems, Vol. 26 No. 5, pp. 87-90.

Lin, Y., Wang, Y. and Kung, L. (2015), "Influences of cross-functional collaboration and knowledge creation on technology commercialization: evidence from high-tech industries", Industrial Marketing Management, Vol. 49, pp. 128-138.

Liu, H., Ke, W., Wei, K. K. and Hua, Z. (2013), "The impact of IT capabilities on firm performance: The mediating roles of absorptive capacity and supply chain agility", Decision Support Systems, Vol. 54 No. 3, pp. 1452-1462.

Mackenzie, S.B., Podsakoff, P.M. and Podsakoff, N.P. (2011), "Construct measurement and validation procedures in MIS and behavioral research: integrating new and existing techniques", MIS Quarterly, Vo. 35 No. 2, pp. 293-334.

Malhotra, A., Gosain, S. and El Sawy, O.A. (2005), "Absorptive capacity configurations in supply chains: gearing for partner-enabled market knowledge creation", MIS Quarterly, Vol. 29 No. 1, pp. 145-187.

Meador, C.L., Guyote, M.J. and Keen, P.G. (1984), "Setting priorities for DSS development", MIS Quarterly, Vol. 8 No. 2, pp. 117-129.

Nunnally, J.C. and Bernstein, I.H. (1994), Psychometric Theory, New York: McGraw-Hill.

Pavlou, P.A. and El Sawy, O.A. (2006), "From IT leveraging competence to competitive advantage in turbulent environments: the case of new product development", Information Systems Research, Vol. 17 No. 3, pp. 198-227.

Pavlou, P.A. and El Sawy, O.A. (2010), "The "third hand": IT-enabled competitive advantage in turbulence through improvisational capabilities", Information Systems Research, Vol. 21 No. 3, pp. 443-471.

Pavlou, P.A., Liang, H. and Xue, Y. (2007), "Understanding and mitigating uncertainty in online environments: a principal-agent perspective", MIS Quarterly, Vol. 31 No. 1, pp. 105-136. 
Phillips-Wren, G., Iyer, L.S., Kulkarni, U. and Ariyachandra, T. (2015), "Business analytics in the context of big data: a roadmap for research", Communications of the Association for Information Systems, Vol. 37, pp. 448-472.

Podsakoff, P.M., MacKenzie, S.B., Lee, J.Y. and Podsakoff, N.P. (2003), "Common method biases in behavioral research: a critical review of the literature and recommended remedies", Journal of Applied Psychology, Vol. 88, pp. 879-903.

Popovič, A., Hackney, R., Coelho, P.S. and Jaklič, J. (2012), "Towards business intelligence systems success: effects of maturity and culture on analytical decision making", Decision Support Systems, Vol. 54 No. 1, pp. 729-739.

Power, D.J. (2008), "Decision support systems: a historical overview", in Handbook on Decision Support Systems, Springer, Berlin Heidelberg.

Raghupathi, W. and Raghupathi, V. (2014), "Big data analytics in healthcare: promise and potential", Health Information Science and Systems, Vol. 2 No. 1, pp. 3.

Riabacke, M., Danielson, M. and Ekenberg, L. (2012), "State-of-the-art prescriptive criteria weight elicitation", Advances in Decision Sciences, vol. 2012, pp. 1-24.

Roberts, N., Galluch, P.S., Dinger, M. and Grover, V. (2012), "Absorptive capacity and information systems research: review, synthesis, and directions for future research", $M I S$ Quarterly, Vol. 36 No. 2, pp.625-648.

Roski, J., Bo-Linn, G. and Andrews, T. (2014), "Creating value in health care through big data: opportunities and policy implications", Health Affairs, Vol. 33 No. 7, pp. 1115-1122.

Ross, J.W., Beath, C.M., and Quaadgras, A. (2013), "You may not need big data after all", Harvard Business Review, Vol. 91 No. 12, pp. 90-98.

Sanders, G.L. and Courtney, J.F. (1985), "A field study of organizational factors influencing DSS success", MIS Quarterly, Vol. 9 No. 1, pp. 77-93.

Santhanam, R. and Hartono, E. (2003), "Issues in linking information technology capability to firm performance”, MIS Quarterly, Vol. 27 No. 1, pp. 125-153.

Schneeweiss, S. (2014). "Learning from big health care data", The New England Journal of Medicine, Vol. 370 No. 23, pp. 2161-2163.

Shanks, G. and Bekmamedova, N. (2012), "Achieving benefits with business analytics systems: an evolutionary process perspective", Journal of Decision Systems, Vol. 21 No. 3, pp. 231-244.

Sharma, R. and Yetton, P. (2003), "The contingent effects of management support and task interdependence on successful information systems implementation", MIS Quarterly, Vol. 27 No. 4, pp. 533-556.

Sharma, R., Mithas, S. and Kankanhalli, A. (2014), "Transforming decision-making processes: a research agenda for understanding the impact of business analytics on organisations", European Journal of Information Systems, Vol. 23 No. 4, pp. 433-441.

Spruit, M., Vroon, R. and Batenburg, R. (2014), "Towards healthcare business intelligence in long-term care: an explorative case study in the Netherlands", Computers in Human Behavior, Vol. 30, pp. 698-707.

Srinivasan, U. and Arunasalam, B. (2013), "Leveraging big data analytics to reduce healthcare costs", IT Professional, Vol. 15 No. 6, pp. 21-28.

Trkman, P., McCormack, K., De Oliveira, M.P.V. and Ladeira, M.B. (2010), "The impact of business analytics on supply chain performance", Decision Support Systems, Vol. 49 No. 3, pp. 318-327.

Wang, Y., and Hajli, N. (2017), "Exploring the path to big data analytics success in healthcare", Journal of Business Research, Vol. 70, pp. 287-299.

Wang, Y., Kung, L., and Byrd, T.A. (2016), "Big data analytics: Understanding its capabilities and potential benefits for healthcare organizations", Technological Forecasting and Social Change, doi:10.1016/j.techfore.2015.12.019. 
Wang, Y., Kung, L., Ting, C. and Byrd, T.A. (2015), "Beyond a technical perspective: understanding big data capabilities in health care", in 48th Hawaii International Conference on System Sciences (HICSS) in Kauai, Hawaii, IEEE, pp. 3044-3053.

Wang, Y., Kung, L., Wang, W.Y.C. and Cegielski, C. (2014), "Developing a big data-enabled transformation model in healthcare: A practice based view', in 34th International Conference on Information Systems (ICIS) in Milan, Italy.

Ward, M. J., Marsolo, K. A. and Froehle, C.M. (2014), "Applications of business analytics in healthcare", Business Horizons, Vol. 57 No. 5, pp. 571-582.

Watson, H.J. (2014), "Tutorial: big data analytics: concepts, technologies, and applications", Communications of the Association for Information Systems, Vol. 34, pp. 1247-1268.

Wixom, B., Yen, B. and Relich, M. (2013), "Maximizing value from business analytics", MIS Quarterly Executive, Vol. 12 No. 2, pp. 111-123.

Wu, L. and Hu, Y.P. (2012), "Examining knowledge management enabled performance for hospital professionals: A dynamic capability view and the mediating role of process capability", Journal of the Association for Information Systems, Vol. 13 No. 12, pp. 976999.

Zahra, S.A. and George, G. (2002), "The net-enabled business innovation cycle and the evolution of dynamic capabilities", Information Systems Research, Vol. 13 No. 2, pp. 147150.

\section{Author Biography}

Yichuan Wang is a Lecturer (Assistant Professor) in Marketing at the Newcastle University Business School. He received his Ph.D. degree from Auburn University. His current research interests are healthcare information technology, big data analytics, and social media marketing. His articles have appeared in Journal of Business Research, International Journal of Production Economics, Industrial Marketing Management, Technological Forecasting and Social Change, International Journal of Information Management, and Journal of Computer Information Systems, among others.

Terry Anthony Byrd is Bray Distinguished Professor of Management Information Systems (MIS) at the Raymond J. Harbert College of Business, Auburn University. He holds a BS in Electrical Engineering from the University of Massachusetts at Amherst and a PhD in MIS from the University of South Carolina. His research has appeared in MIS Quarterly, Journal of Management Information Systems, European Journal of Information Systems, Decision Sciences, Information Systems Journal, Journal of Association of Information Systems and other leading journals. His current research interests focus on the design, development, implementation, diffusion, and infusion of information technology in facilitating a variety of individual, group organizational and societal behaviors and initiatives to achieve positive results, especially in the healthcare domain. 